hernia $^{7}$ has the advantage of allowing any other intraabdominal lesion to be treated. Good results have been reported from the transthoracic approach. ${ }^{8}$ In the absence of associated duodenal ulcer there is little evidence to suggest that patients with reflux oesophagitis have greater than normal secretion of acid, and though there are advocates of vagotomy with gastric drainage in addition to repair of the hiatus there is no convincing proof that this is necessary. Indeed, D. A. W. Edwards and his colleagues, ${ }^{9}$ in a dispassionate review carried out by a group of physicians of these surgical procedures, found little to choose between patients who had undergone transthoracic and those who had transabdominal repair, while surgical attempts to reduce acid secretion did not seem to improve the results. During an 11 -year period they found that 50 of their 63 patients who

\section{All that Sweetens is not Sugar}

Artificial sweeteners have a place in modern food technology, particularly in the manufacture of soft-drink concentrates. They may make eating and drinking more tolerable for a diabetic with a sweet tooth and help the non-abstemious to keep their waistlines within limits. But for some reason the use of artificial sweeteners, particularly cyclamates, as sugar substitutes in food other than soft drinks and preparations for diabetics is slight in Great Britain despite a more extensive use among weight-conscious Americans.

About two years ago the safety of cyclamates in food was questioned when it was discovered that under some conditions some animals and some people apparently metabolized the cyclamates and excreted cyclohexylamine in the urine. This suggested that more cyclamate was being absorbed from the gut than had previously been believed. However, the evidence now indicates that any conversion of cyclamate to cyclohexylamine that does occur is carried out in the gut by the microflora. This would explain the irregular appearance of the metabolite.

Little is known about the short- or long-term toxic effects of cyclohexylamine, but experiments to gain this information are in progress. If cyclohexylamine is found to have some undesirable properties they should be taken seriously. At the same time it is possible that intestinal bacteria may produce other undesirable metabolites. It is not surprising, therefore, to learn that an increasing interest is now being taken in the metabolic activity of these numerous and variable commensals of man.

Animal experiments recently reported suggest new and at first sight a rather frightening toxic effect from large doses of cyclamates. ${ }^{1}$ Young female hamsters given large doses of calcium cyclamate by mouth two to three times daily for two weeks showed a $75 \%$ mortality and had calcifying lesions in muscle, including the myocardium, and the kidneys. Other calcium salts-acetate, aspartate, or ascorbate-did not produce this effect. No tests were done with sodium cyclamate, which is also used as a sweetener-the calcium salt being preferred since it is more suitable for patients on low-sodium

1 Bajusz, E., Nature, 1969, 223, 406.

British Medical fournal, 1968, 1, 594.

Berryman, G. H., Hazel, J. D., Sanders, P. G., and Weinberg, M. S. American fournal of Clinical Nutrition, 1968, 21, 673.

- National Research Council, Non-Nutritive Sweeteners: An Interim Report to the U.S. Food and Drug Administration. Washington. 1968. had been operated on, all with severe reflux resistant to medical treatment, were well pleased with the operative result. Thus the chances that the symptoms of reflux will be relieved by surgery are high even when only the most severe cases are submitted to operation.

1 Adler, R. H., Surgery, Gynecology and Obstetrics with International

${ }^{2}$ Abstracts of Surgery, 1963, 116, 1. $1959,25,91$.

3 Mann, C. V., Greenwood, R. K., and Ellis, F. H., Surgery, Gynecology and Obstetrics, 1964, 118, 853

- Atkinson, M., British Medical fournal, 1967, 4, 218

Cocco, A. E., and Brantigan, O. C., Annals of Surgery, 1969, 169, 857. Silber, W., Review of Surgery, 1969, 26, 1.

Clagett, O. T., Annals of the Royal College of Surgeons, 1966, 38, 195. Zellos, S., Thorax, 1966, 21, 295.

Edwards, D. A. W., Phillips, S. F., and Rowlands, E. N., British Medical fournal, 1964, 2, 714 . diets. In experiments lasting only two weeks it seems regrettable that this control observation was omitted. How seriously should these observations be taken ?

Cyclamates are one of the most widely tested of those compounds which have been used as food additives. ${ }^{2}$ Of the animal kingdom, mice, rats, cats, rabbits, dogs, and primates, including man, have been extensively studied after receiving large doses for long periods, with generally negative results. It is perhaps salutary to remember that if thiourea had first been tested on rats or penicillin on guinea-pigs neither of these useful drugs might ever have been given a clinical trial. However, before the sensitivity of these species to the toxic effects of these two drugs had been recognized studies on patients had already shown them to possess a satisfactory margin of safety. The same can now reasonably be said of cyclamates. Not only have healthy people received daily doses exceeding the maximum acceptable daily intake $(5 \mathrm{~g}$. for an adult), but specially vulnerable groups-diabetics and patients with renal or gastrointestinal disorders-have been given doses up to that level and no adverse effects attributable to cyclamates have been observed. ${ }^{3}$

The use of cyclamates in the U.S.A. increased from 5 million $\mathrm{lb}$. (2.3 million $\mathrm{kg}$.) in 1963 to 15 million $\mathrm{lb}$. $(6 \cdot 8$ million kg.) in 1967 . Of this $70 \%$ is in soft drinks. In a special survey the average daily intake in children aged 8-11 years was 0.59 g., and the highest observed daily intake was $3.5 \mathrm{~g}$. It was concluded that during the week in July in which the survey was taken there was a $95 \%$ probability that no more than $2.5 \%$ of the population aged 1-18 years consumed more than $1 \mathrm{~g}$. of cyclamate each day. ${ }^{4}$

In the U.K., according to the Ministry of Agriculture, Fisheries and Food, cyclamates are used only in soft drinks or in sweetening tablets. At the maximum levels permitted in drinks it can be calculated that a child would need to consume about five large glassfuls of a sweetened drink each day to reach the maximum acceptable daily intake of $5 \mathrm{~g}$., but at the levels actually used by British manufacturers the consumption would have to be from 15 to 30 large glassfuls to achieve this level of intake. A mild laxative effect from the unabsorbed cyclamate is the earliest evidence of excessive intake, and few doctors would argue with the use of a food additive that might reduce the vast demand of much more undesirable laxatives and purgatives.

However, since the regulatory bodies in both the U.K. and the U.S.A. place some emphasis on the desirability of keeping 
individual consumption below cerrtain levels, there would seem a good case for making the manufacturers disclose the nature and quantity of artificial sweeteners added to soft drinks. This can operate only in their own interests, and, while most consumers will pay no heed to the information, those who are concerned about their own or their children's health will at least be able to make the calculations necessary to assure themselves that their consumption is within recommended limits.

It is satisfactory to know that the British Industrial Biological Research Association is keeping a watchful eye on cyclamates as on other actual and potential food additives. Not only does the association publish regular critical and unprejudiced surveys of published work from all parts of the world but it is engaged in some of the crucial animal tests for safety. The Government has shown its confidence in the value of this research association in protecting public health by the size of the grant which it awards.

\section{Attack on Cholera}

Up to the middle of this century cholera was being gradually contained within its endemic areas in India and East Pakistan, but large epidemics in Egypt in 1947 and in Thailand in 1958 showed that the smouldering fires could still light up conflagrations in other countries. These epidemics attracted attention from groups of American workers, whose studies shed new light on the pathogenesis and treatment of cholera. When, in more recent years, cholera caused by the El Tor variant ${ }^{1}$ of the vibrio began to spread through the Far East from an endemic focus in Indonesia and then swept back westwards to involve India (where it has supplanted infection with the classical strain), the Middle East, and southern Russia, world-wide interest was aroused, and now large-scale studies into the pathogenesis, epidemiology, and control of the disease are being sponsored by the World Health Organization, the National Institutes of Health in the U.S.A., and similar bodies in India, Japan, and elsewhere.

The Cholera Research Laboratory established under the joint auspices of the South-east Asia Treaty Organization (S.E.A.T.O.) and Pakistan, with strong American support, has been in the forefront of investigations into all aspects of cholera and has lately published a series of three papers on controlled vaccine trials carried out in 1966-7.23 Having shown in earlier studies that a vaccine of high antigenic potency could give good protection (60-80\% effectiveness), and that cholera occurs predominantly in children, with the highest case rate among those under 5, the team at the Cholera Research Laboratory designed a new vaccine trial in a more extended population but limited to children aged 3 months to 14 years. A commercial cholera vaccine with a combined diphtheria and tetanus toxoid as a control was given in one- and two-dose schedules to some 40,000

British Medical fournal, 1966, 1, 1555.

Mosley, W. H., et al., Bulletin of the World Health Organization, $1969,40,177$.

s Mosley, W. H., McCormack, W. M., Ahmed, A., Alauddin Chowdhury, A. K. M., and Bauri, R., Bulletin of the World Health Organization, 1969, 40, 187.

- McCormack, W. M., Mizanur, A. S. M., Alauddin Chowdhury, A. K. M., Mosley, W. H., and Phillips, R. A., Bulletin of the World Health Organization, $1969,40,199$.

- World Health Organization Technical Reports Service, 1969, No. 414.

- Freter, R., in Proceedings of the Cholera Research Symposium, ed. O. A. Bushnell, p. 222. Washington, Public Health Service Publication No. 1328. 1965. children in an endemic rural area. The children were stratified in three age groups, 0-4 years, 5-9 years, and 10-14 years, and were assigned in strict alternation to one of three schedules: two doses of diphtheria and tetanus toxoid, one dose of cholera vaccine with one dose of diphtheria and tetanus toxoid, and two doses of cholera vaccine. Two children were assigned to the double dose of cholera vaccine for one each on the other two schedules. All vaccines were given by a jet-injector, and the vaccination programme was carried out during 20 September to 17 November 1966.

The first cholera cases (acute diarrhoea detected by daily family visits and confirmed bacteriologically) occurred in November, and the epidemic wave quickly reached its peak in December-January, gradually subsiding over the next four months. From analyses of the findings over the sevenmonth period it was apparent that two doses of the cholera vaccine were needed to give maximum protection (91\%) to the youngest age group, that this protection lasted for only three months, and that one dose gave at least as good protection as two doses to children aged 5-14 years, with immunity waning in the later months of the epidemic. The data indicate that among preschool children highly exposed to infection in an endemic area two doses of a cholera vaccine will give only short-lived protection, whereas in older children one dose will act as a not very efficient booster in an age group already well "salted" by latent infection. Indeed, it is reckoned from this and other studies that the ratio of clinical to latent cholera infection in an endemic area may range from $1: 20$ to $1: 100$.

As part of this vaccine study specimens of blood collected by finger-tip puncture in a capillary pipette were taken from random samples of the test community before vaccination and during and after the epidemic season. The sera were tested for vibriocidal antibody by a technique which seemed to give reproducible results. Earlier it had been shown that there was a' steady rise in vibriocidal antibody titres with increasing age and that this rise in antibody was correlated inversely with a fall in the case-rate. In the current study the antibody titres in the age group 0-4 years were significantly higher in the children given two doses than in those given one dose, but there was no such difference in the older age groups. These findings, with other evidence, indicate that the level of vibriocidal antibody in a population is a good measure of the degree of immunity to cholera whether naturally or artificially acquired. In the third paper in this series $^{4}$ the authors assessed the clinical severity of cholera in relation to the vaccination status and found no correspondence between these two measurements. This suggests that good antibody titres will not protect individual children against the onslaught of a really heavy infection. Thus in its epidemiology cholera has many features in common with other acute infections.

There have so far been reports on six controlled trials Iwith 13 different cholera vaccines in three areas (East Pakistan, Calcutta, and the Philippines), and the summation of the results shows that some cholera vaccines give protection in the range of $40-80 \%$ for a period of three to six months. This level of achievement is not satisfactory as a public health measure for the control of the disease, particularly in non-endemic areas. In endemic areas, one booster dose for schoolchildren given immediately before the expected epidemic season could be recommended if the machinery for large-scale immunization is available. But clearly improvements will have to be made in the antigenicity of parenteral vaccine-for example, by using purified frac- 